\title{
Optimal Control of Workpiece Thermal State in Creep-Feed Grinding Using Inverse Heat Conduction Analysis
}

\author{
Marin Gostimirović1,* - Milenko Sekulić1 - Janez Kopač ${ }^{2}$ - Pavel Kovač 1 \\ 1 University of Novi Sad, Faculty of Technical Science, Serbia \\ 2 University of Ljubljana, Faculty of Mechanical Engineering, Slovenia
}

\begin{abstract}
Due to intensive friction between grinding particles and workpiece material, a substantial quantity of thermal energy develops during grinding. Efficient determination of real heat loading in the surface layer of the workpiece material in grinding largely depends on the reliability of basic principles of distribution of heat sources and the character of the temperature field within the cutting zone. Therefore, this paper takes a different approach towards the identification of the thermal state of the creep-feed grinding process by using the inverse problem to approximate heat conduction. Based on a temperature measured at any point within a workpiece, this experimental and analytical method allows the determination of a complete temperature field in the workpiece surface layer as well as the unknown heat flux on the wheel/ workpiece interface. In order to solve the inverse heat conduction problem, a numerical method using finite differences in implicit form was used.

When the inverse heat conduction problem is transformed into an extreme case, the optimization of heat flux leads to an allowed heat loading in the surface layer of workpiece material during grinding. Given the state function and quality criterion, the control of workpiece heat loading allows the determination of optimal creep-feed grinding conditions for particular machining conditions.
\end{abstract}

(C)2011 Journal of Mechanical Engineering. All rights reserved.

Keywords: creep-feed grinding, head loading, inverse problem, optimal control

\section{INTRODUCTION}

Grinding is considered as one of the most important machining methods. In addition to the conventional fine multi-pass grinding, there has been a recent introduction of high-productivity grinding methods. These high-productivity methods use higher cutting speeds and/or larger cutting depths in order to increase the relatively low productivity which has traditionally been considered the main drawback of conventional grinding. However, the increase of grinding conditions considerably changes the grinding kinematics, i.e. the conditions in the wheel/ workpiece interface [1].

High-speed grinding is characterized by lower cutting depths and shorter time of contact between the workpiece material and grinding particles, with a more intensive friction in the cutting zone. The increased contribution of friction in the generation of the total quantity of thermal energy also increases the contact temperature. The potential decrease of contact temperature during extremely high-speed machining can be attributed to a reduced cross-section of chip and faster introduction of the next grinding particle into the wheel/worpiece interface [2]. This improves cutting conditions because of reduced friction and deformation during chip forming due to interfacing between the grinding particles and the softened material layer generated by previous grinding.

In creep-feed grinding, which is characterized by large cutting depths and small workpiece speeds, there is a longer wheel/ workpiece interface as well as a prolonged time of contact with workpiece material. At the same time, this results in the generation of more intensive heat sources in grinding particles and a prolonged time of their effect. In addition, a longer interface contributes to a better evacuation of heat from the cutting zone, which results in a decreased power of heat source per unit area [3] and [4]. Also, a small workpiece speed improves the distribution of total thermal energy within the cutting zone due to its prolonged effect. All this results in an increased total quantity of thermal energy per unit area but over a longer time period. 
Based on the previous discussion, it is evident that high-productivity grinding methods cause the development of large quantities of thermal energy within the cutting zone [5]. The generated thermal energy, located within a relatively narrow area of the cutting zone, causes high cutting temperatures in creep-feed grinding. These increased temperatures instantaneously burst to a maximum, have short duration and exert a pronounced negative effect on wheel surface, workpiece quality and accuracy.

Since the main task of grinding is to achieve satisfactory part quality with as large productivity as possible, special attention is focused on the effect that grinding temperatures have on the change of material properties in the workpiece surface layer. If the temperatures thus generated are high enough to cause structural and phase transformations of the workpiece material, the machined surface shall suffer from a number of disadvantages. Should, in addition, dimensional errors appear as well, the overall effect can substantially diminish exploitation features of the finished part.

Efficient control of thermal phenomena in grinding, i.e. the determination of allowed heat loading on workpiece surface layer, requires knowledge of heat development and distribution in grinding, the temperature field in the cutting zone and, finally, the influence of cutting conditions on grinding temperature [6]. For that reason, identification of the thermal state in grinding based on analytical models and experimental results has been gaining popularity.

As the research so far has shown, nonstationary and non-linear technical processes involving intensive heat conduction, such as creep-feed grinding, can be successfully solved using a novel approach based on inverse problem of heat transfer [7]. The inverse problem of heat transfer allows the closest possible experimentalmodel approximation of thermal regimes for grinding.

In the case of control over the grinding thermal regime, the extreme case of the inverse problem of heat conduction [8] is practically the only way to reliably approximate the allowed heat loading on the workpiece surface layer. For a known temperature measured at a point within the workpiece surface layer, numerical methods are used to approximate the total temperature field of the surface layer as well as the unknown heat flux density on the wheel/workpiece interface [9] and [10]. For the selected quality criteria, particular machining conditions, and a predetermined loading on the workpiece surface layer, it is possible to arrive at optimal cutting conditions in creep-feed grinding by controlling the heat flux.

\section{PARAMETERS OF GRINDING HEAT SOURCE}

The role of mathematical theory behind thermal phenomena in grinding is to adopt the most adequate model of the workpiece, grinding wheel and their inter-relationships, Fig. 1. It can be assumed that the elementary heat source on the grinding particle is the result of friction between the grinding particle, workpiece and chip in the workpiece material shear plane. Summing up all the heat sources, i.e. grinding particles in contact with the workpiece, gives the total heat source for the entire cutting zone, $q_{T}$. This total heat source, whose strength varies within a narrow range, acts continuously, shifting across the workpiece surface with constant velocity [5] and [6].

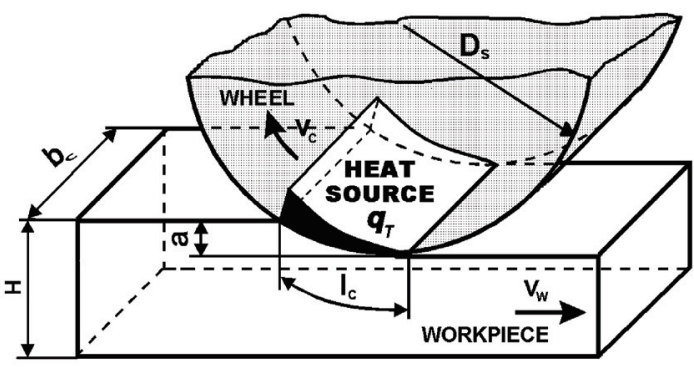

Fig. 1. Model of thermal state in creep-feed grinding

The heat source in grinding is characterized by its power and length of activity. Magnitudes of these two parameters depend on the machining process, wherein cutting conditions have the predominant influence.

Heat source power in the cutting zone is the basic source parameter since it predominantly impacts the thermal state of the workpiece surface layer. An analytical definition of heat source power starts from the fact that in grinding the total 
mechanical work applied to the cutting process is transformed into thermal energy:

$$
Q_{T}=F_{t} \cdot v_{c} \cdot t_{e},
$$

where $F_{t}$ is the tangential grinding force, $v_{c}$ is the cutting speed, and $t_{e}$ is the time of contact between the grinding particles and workpiece.

The total heat quantity, Eq. (1), is transformed into heat flux density:

$$
q_{T}=\frac{Q_{T}}{\iint_{A_{c}} d x d y \int_{t_{e}} d t}=\frac{F_{t} \cdot v_{c}}{A_{c}} .
$$

If, in Eq. (2), the wheel/workpiece interface is decomposed into $A_{c}=l_{c} \times b_{c}=\left(a \times D_{s}\right)^{1 / 2} \times b_{c}$, and the tangential grinding force is reduced to a unit grinding width $b_{c}$, that is, we introduce the specific tangential grinding force $F_{t}^{\prime}=F_{t} / b_{c}$, then:

$$
q_{T}=\frac{F_{t}^{\prime} \cdot v_{c}}{\sqrt{a \cdot D_{s}}}
$$

On the other hand, the specific tangential grinding force can be expressed by a general Eq.:

$$
F_{t}^{\prime}=k_{s m} \cdot h_{m}
$$

where $h_{m}=v_{w} \times a / v_{c}$ is the mean cutting depth, and $k_{s m}$ is the mean specific cutting force.

The final form for total heat flux density as a function of the grinding conditions can be derived by substituting Eq. (4) in Eq. (3):

$$
q_{T}=k_{s m} \cdot v_{w} \sqrt{\frac{a}{D_{s}}} .
$$

On the other hand, the total active time interval of the heat source has a prominent influence on the heat quantity being evacuated from the cutting zone into the workpiece. The shorter active time of the heat source diminishes the heat quantity transferred via the wheel/ workpiece interface into the workpiece surface layer, while at the same time allowing a faster supply of coolant onto the freshly ground surface. This time interval is expressed as the ratio between the interface length $l_{c}$ and workpiece velocity $v_{w}$, that is:

$$
t_{T}=\frac{\sqrt{a \cdot D_{s}}}{v_{w}} .
$$

\section{INVERSE PROBLEM OF THE GRINDING PROCESS}

The process of heat transfer between solid bodies or between a system and its environment, of which heat conduction in grinding is also a part, is mostly considered from the standpoint of mutual relations between the input and output process parameters.

If the input parameters $u(t)$ are known and the output parameters $z(t)$ define the process state in time, then the output parameters are a function of the input parameters, i.e.:

$$
z=f(u, t) .
$$

If, for the adopted thermal model, there exist unique conditions, then the determination of the input-output relationship is the direct task of heat conduction. Conversely, the inverse heat conduction solves the problem of finding the input characteristics of the process for the known temperature field [7].

If for every unknown parameter $u$ there is a linear, smooth operator $A$ which allows the determination of the output parameter $z$, then the general case of the inverse problem is formulated by the following Eq.:

$$
A \times u=z .
$$

\subsection{Case of the Inverse Problem in Grinding}

In grinding, considering that the cutting depth is many times smaller than the length and width of the wheel/workpiece interface, the heat source can be treated as a strip of infinite length and constant heat distribution. Furthermore, if the dissipation of heat flow in the direction of heat source movement is disregarded, then the workpiece can be approximated with a series of adiabatic thin plates, Fig. 2.

Substitution of the real workpiece with the semi-infinite plate is completely justified, bearing in mind that the heat source in grinding is generated within a small volume of workpiece material while the heat loading of the surface workpiece layer is considered depth-wise. 


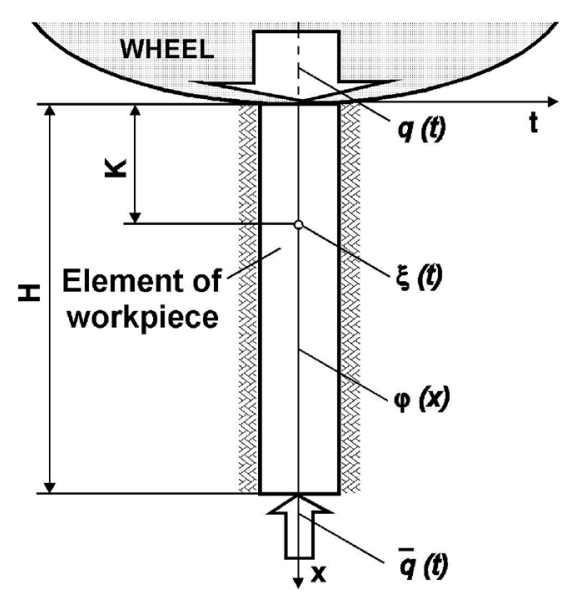

Fig. 2. Schematic of a uni-dimensional inverse problem in grinding

For such a defined thermal model of grinding, the following is the differential equation of a one-dimensional heat conduction, for $x \in(0, H)$ and $t \in\left(0, t_{m}\right]$ :

$$
\rho c(\theta) \frac{\partial \theta}{\partial t}=\frac{\partial}{\partial x}\left(\lambda(\theta) \frac{\partial \theta}{\partial x}\right),
$$

where $\theta=\theta(x, t)$ is the workpiece temperature at point coordinate $x$ at moment $t, \lambda=\lambda(\theta)$ is the heat transfer coefficient, $\rho c=C(\theta)$ is the specific heat capacity ( $\rho$ - material density, $c$ - specific heat), $H$ is the thickness of the surface layer of workpiece material, and $t_{m}$ is the largest time increment.

Now the analytical form of the inverse problem of heat conduction for surface grinding can be described with Eq. (9), in conjunction with initial conditions, additional conditions and boundary conditions.

The initial temperature distribution in the workpiece for the initial moment $t=0$ is:

$$
\left.\theta(x, t)\right|_{t=0}=\phi(x) .
$$

An additional condition is the fact that at the point $x=K(0<K \leq H)$, there is a known temperature, measured during a time interval:

$$
\left.\theta(x, t)\right|_{x=H}=\xi(t) .
$$

Boundaries of the considered workpiece surface layer are defined by the known heat flux density:

$$
-\left.\lambda(\theta(x, t)) \frac{\partial \theta(x, t)}{\partial x}\right|_{x=H}=\bar{q}(t),
$$

and unknown heat flux density:

$$
-\left.\lambda(\theta(x, t)) \frac{\partial \theta(x, t)}{\partial x}\right|_{x=0}=q(t) .
$$

The final solution of the inverse problem is the heat flux density on wheel/workpiece interface $q(t)$ (part of total heat flux density [3]), and the temperature field $\theta=\theta(x, t)$ throughout the elementary parts of the workpiece, $D=\{(x, t)$ : $\left.x \in[0, H], t \in\left[0, t_{m}\right]\right\}$.

Due to their complexity, differential equations, which describe the process of heat conduction in grinding, are mostly solved using numerical methods. The first step with every numerical method is the discretization of space, i.e. the approximation of a thin, isolated plate of the workpiece by a number of elementary pieces $\Delta x$, Fig. 3. When dealing with a non-stationary -heat conduction problem, the time of temperature change and heat flux is discretized by a $\Delta t$ increment.

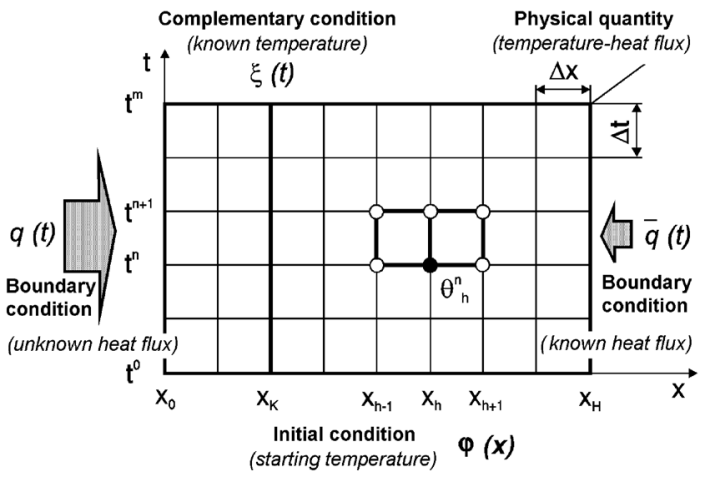

Fig. 3. The shape of a uni-dimensional mesh of heat conduction inverse problem

To solve the partial differential equation shown in Eq. (9) an implicit form of the finite differences method was chosen [8]. A system of linear algebraic equations is used to calculate the unknown heat flux $q^{n+1}$ on workpiece surface and the temperature field of the workpiece surface layer $\theta_{h^{n+1}}(h=0,1, \ldots, K-1, K+1, \ldots, H)$ as follows:

$$
[\mathbf{R}] \cdot\{\boldsymbol{\Theta}\}=\{\mathbf{B}\} .
$$


Solving the matrix system shown in Eq. (14) requires the initial task to be divided into two parts.

First, a standalone system is calculated:

$$
\left[\mathbf{R}_{2}\right] \cdot\left\{\boldsymbol{\Theta}_{2}\right\}=\left\{\boldsymbol{B}_{2}\right\} .
$$

The matrix Eq. (15) is solved as the direct task of heat conduction within the area $D_{2}=\{(x, t)$ : $\left.x \in[K, H], \mathrm{t} \in\left[0, t_{m}\right]\right\}$. The solution yields the unknown temperatures $\theta_{h^{n+1}}(K+1, \ldots, H)$.

Once vector $\boldsymbol{\Theta}_{2}$ is determined, the problem of inverse heat conduction in the area of $D_{1}=\{(x, t)$ : $\left.x \in[0, K], \mathrm{t} \in\left[0, t_{m}\right]\right\}$ can be tackled by using the system:

$$
\left[\mathbf{R}_{1}\right] \cdot\left\{\boldsymbol{\Theta}_{1}\right\}=\left\{\mathbf{B}_{1}\right\} .
$$

From the system shown in Eq. (16), starting from the first unknown temperature $\theta_{K-1}^{n+1}$, vector $\boldsymbol{\Theta}_{1}$ is calculated. This vector represents the unknown heat flux $q^{n+1}$ and the unknown temperature $\theta_{h^{n+1}}(h=0, \ldots, K-1)$.

\subsection{Extreme Case of the Grinding Inverse Problem}

One of the possible ways to solve the inverse problem is to transform it into an extreme case using some method of optimization. Given the input parameters, this would allow us to determine the allowed thermal state of the process for the analytical model in hand, so as to satisfy the state and boundary functions for the given optimization criterion.

For grinding, the task of optimal heat loading control is to determine the function of the process state, $\theta=\theta(x, t)$, and the control function $q=q(t)$, so as to satisfy the analytical form of the inverse problem for the grinding process, as defined by Eqs. (9) to (13). These functions are determined under the condition that the known temperature at a particular fixed point $\bar{\theta}(t)=\theta(K, t)$ is consistent with the temperature $\hat{\theta}(q, K, t)$ which is calculated based on control function $q(\underline{t})$ :

$$
J(q)=\int_{0}^{t_{m}}[\hat{\theta}(q, K, t)-\bar{\theta}(K, t)]^{2} d t .
$$

In order to minimize the differences between the known and the calculated temperatures, an iterative method of optimization is used.

$J\left(q_{i}\right)$ is calculated by applying the iterative optimization algorithm for particular values of functional $q_{i}(t)$. The procedure is repeated, decreasing the value of the functional $J\left(q_{i+1}\right)<J\left(q_{i}\right)$, until its minimum is reached. The iterative gradient method procedure is considered finished for a sufficiently small functional, which means that the calculated vector components and the measured temperatures are very close.

\section{EXPERIMENTATION}

\subsection{Experimental Setup}

The experimental work was carried out on a surface creep-feed grinding machine $»$ Majevica» type CF 412 CNC.

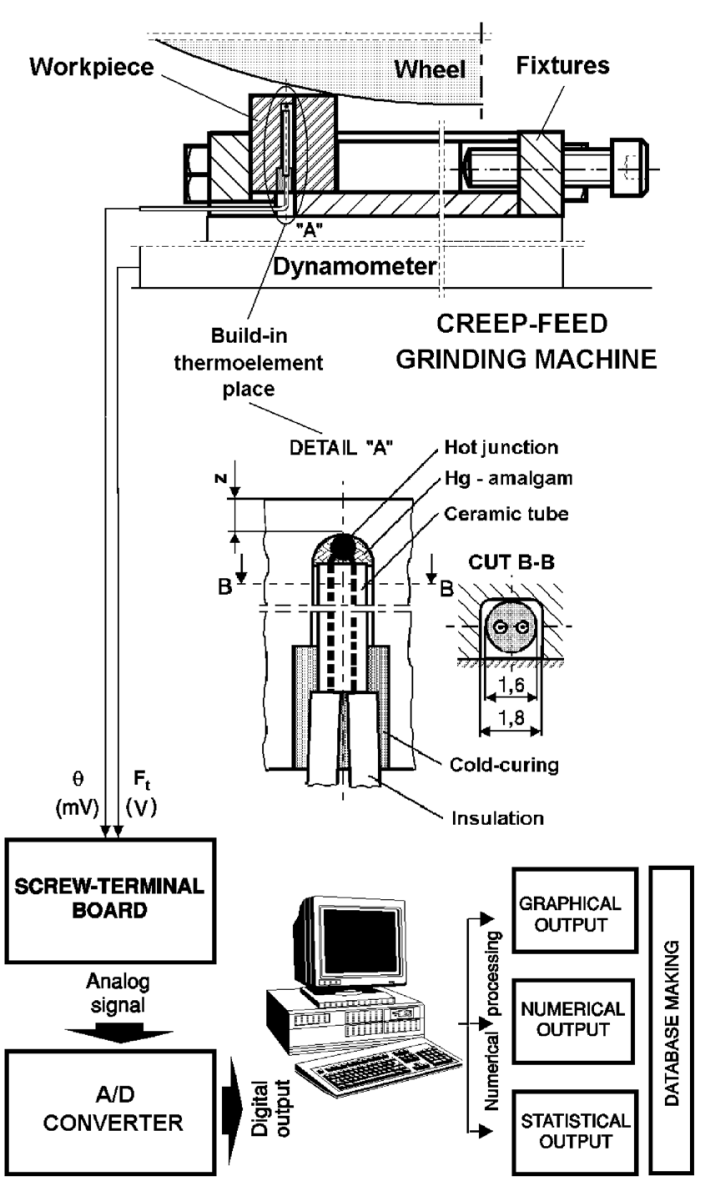

Fig. 4. Measuring system of grinding process 
The workpiece material was high-speed steel (DIN S 2-10-1-8 or B.S. BM 42) at $66 \mathrm{HRc}$ hardness, with dimensions of the parts $40 \times 20 \times 16$ $\mathrm{mm}$. The test used an aluminum oxide wheel »Winterthur« type 53 A80 F15V PMF, size $400 \times 50 \times 127 \mathrm{~mm}$. The depth of cut was $a=0.05$; $0.1 ; 0,25 ; 0.5$ and $1 \mathrm{~mm}$, the workpiece speed was $v_{w}=2.5 ; 5 ; 10 ; 25$ and $50 \mathrm{~mm} / \mathrm{s}$ and the wheel speed was $v_{s}=30 \mathrm{~m} / \mathrm{s}$. A water-based coolant (emulsion 6\%) was used during the grinding test with a flow rate of $175 \mathrm{l} / \mathrm{min}$.

The temperature was measured in the workpiece surface layer using a thermocouple (type $\mathrm{K}, \varnothing 0.2 \mathrm{~mm}$ ) built into the workpiece at a specified clearance from the wheel/workpiece interface area. Measuring, analysis and control of the temperatures and forces during the process of machining with grinding was performed with the help of a computerized measuring system, Fig. 4.

Metallographic identification of the state of the workpiece material surface layer after grinding was performed with an optic microscope.

\subsection{Experiment Results}

To determine the temperature field distribution in the workpiece surface-layer, temperatures in the workpiece were measured for various distances from the measuring point to the contact surface of the workpiece and the grinding wheel. A characteristic graphic review of how creep-feed grinding temperatures change in time in the cutting zone, obtained through gradually drawing the grindstone closer to thermocouple's hot junction, is shown in Fig. 5.

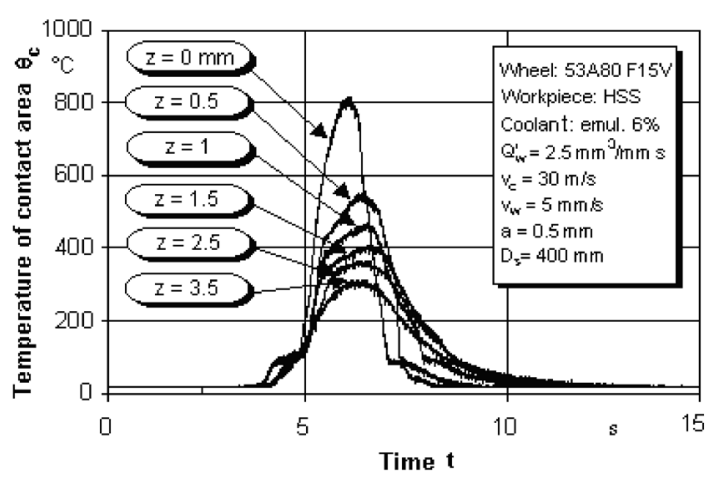

Fig. 5. Creep-feed grinding temperature within the workpiece material surface layer
Metallographic examination of changes in the microstructure of the workpiece surface layer show that secondary changes appeared in each case when the measured maximal grinding contact temperature was higher than the temperature of the previous remission, which is $\theta_{c}=550{ }^{\circ} \mathrm{C}$ for the steel that was used in this testing, Fig. 6.

The measured microhardness indicates that the microhardness of the secondary hardened layer is a little higher than the microhardness of the basic material. The smallest measured value of microhardness is found in the secondary remission layer.

During further inspection of the workpiece material surface layer condition, not one sample was found with microcracks in it. On the other hand, burned surfaces were noticed in all samples where the measured grinding contact temperature was above the temperature of the previous remission.
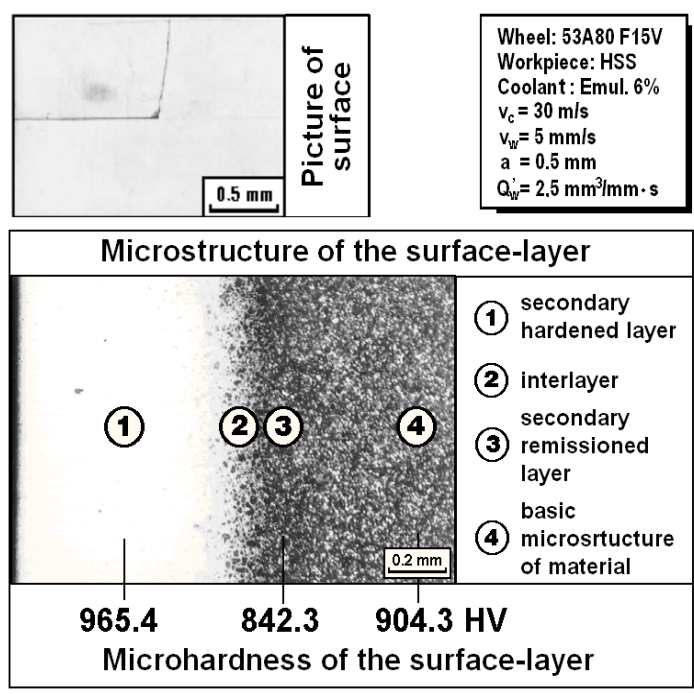

Fig. 6. Metallographic picture of workpiece material surface layer after creep-feed grinding

Shown in Fig. 7 is an experimentally obtained dependence between the depth of the secondary changed surface layer of high-speed steel and the grinding conditions, for a constant specific productivity. The diagram shows the maximum measured temperature in the surface layer of workpiece material. 


\section{OPTIMAL CONTROL OF WORKPIECE THERMAL STATE IN GRINDING}

\subsection{The Results of the Inverse Problem Method}

In this case of verification, to calculate the workpiece heat loading by inverse heat conduction problem, the known temperature distribution at a depth of $\mathrm{z}=1 \mathrm{~mm}$ was taken for the additional boundary condition, Fig. 5. Based on the experimental results, and considering the process boundary conditions and thermal/physical characteristics of grinding, the parameters of the heat source in creep-feed grinding was obtained by computation.

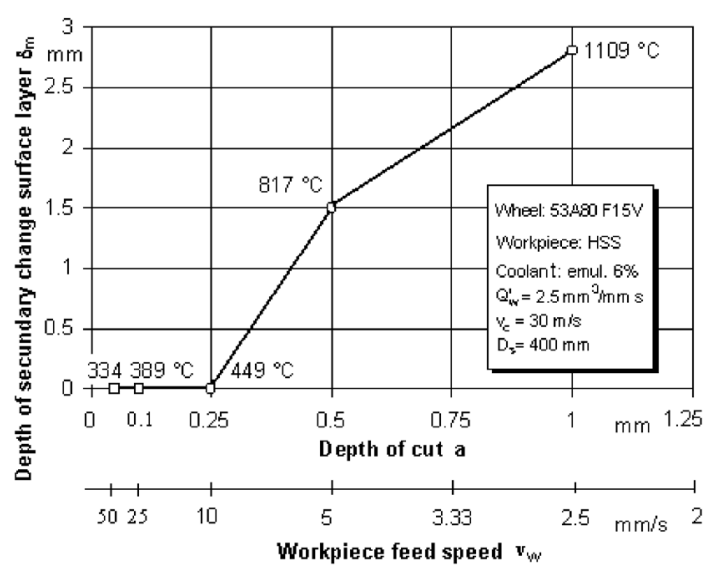

Fig. 7. Secondary changes in the surface layer of $H S$ steel as the function of creep-feed grinding conditions

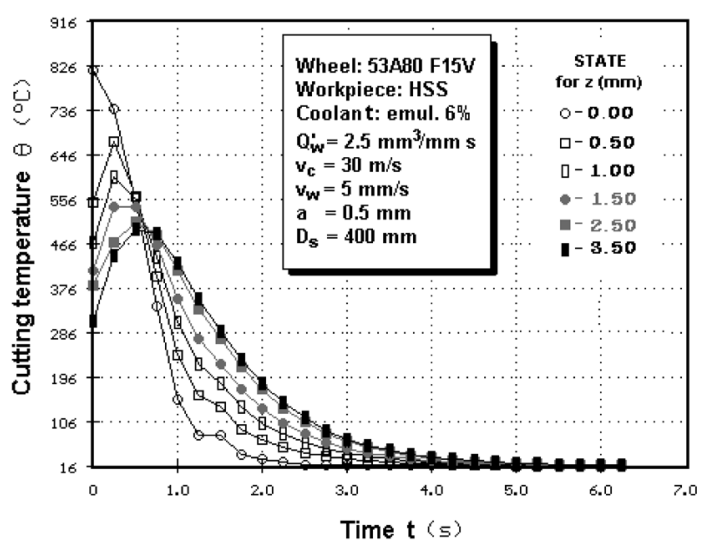

Fig. 8. Computation of temperature change over time in the workpiece material surface layer
The total temperature field in the workpiece material surface layer was obtained by computation, Fig. 8., as well as the heat flux density in the wheel/workpiece interface, Fig. 9.

The computed distribution of heat flux density over the interface area clearly shows the direct relationship between heat source parameters, i.e. the power of the heat source and its total active time.

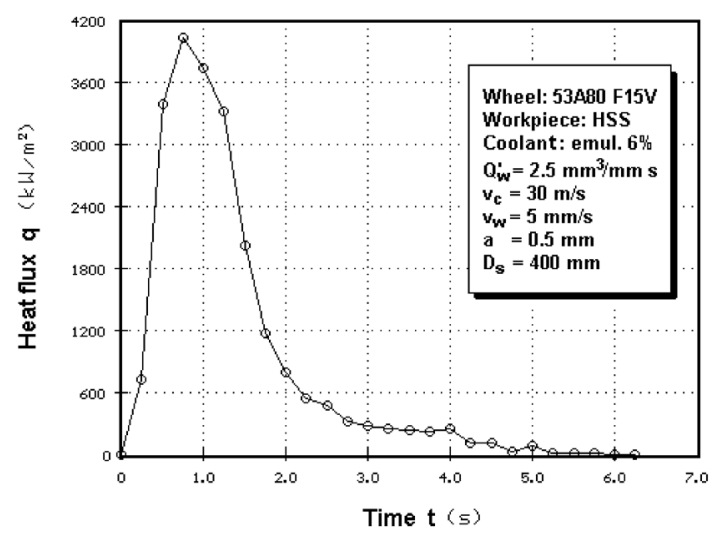

Fig. 9. Heat flux density over the wheel/workpiece interface

\subsection{Process System for Optimal Control}

Optimization of creep-feed grinding conditions by the extreme case of the inverse method relies on heat source parameters. The process of optimization is the determination of the most favorable ratio between the heat source power and its active time, for the heat flux density over the interface area, Fig. 10a.

Under the condition of maximum specific machining productivity $\left(Q_{w}{ }^{\prime}=v_{w} \cdot a=\max \right)$, the process of optimization is conducted by completely searching the bounded solution space $\left(v_{w}, a\right)$, Fig. 10b. Thus optimal cutting depth a and workpiece velocity vw are determined. They can either be inside or on the very boundary of the search space.

Based upon the proposed model of optimization, Eqs. (9) to (13), the criterion of optimization in Eq. (17), the state functions in Eqs. (5) and (6) and boundaries, a software application was made. In order to verify the proposed model of optimal control in creep-feed grinding, testing was performed, which involved a variation of input data. Partial results are shown in Table 1. 


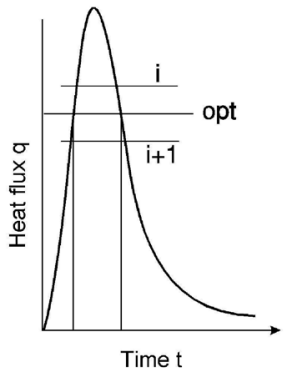

a)

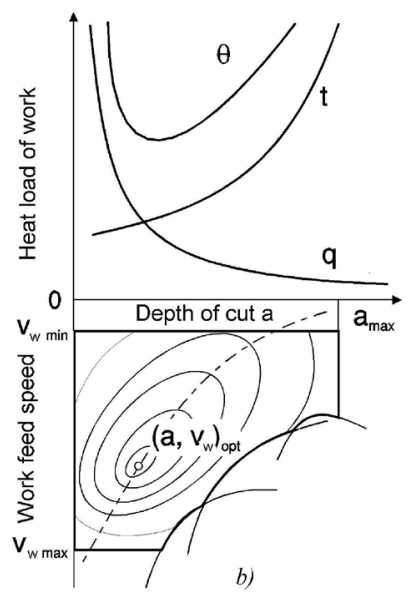

Fig. 10. Algorithm of optimization cutting conditions by control of heat loading in the workpiece

\section{ANALYSIS OF RESULTS}

The computed time and depth-related change of temperature in the interface zone of the workpiece surface layer shows a high degree of conformity with the experimentally obtained results. Shown in Fig. 11 is the change of the interface temperature obtained both analytically and experimentally. A similar trend of analytically and experimentally obtained temperature changes over time is applicable to any other point within the workpiece.

High computation accuracy of the wokpiece temperature field also implies reliability of the computed heat flux density (Fig. 9).

The comparison between the computed optimal creep-feed grinding conditions with the allowed ones, which were derived experimentally, shows very little differences. The differences can be explained by a large number of parameters which had to be estimated in the course of modeling the grinding process.

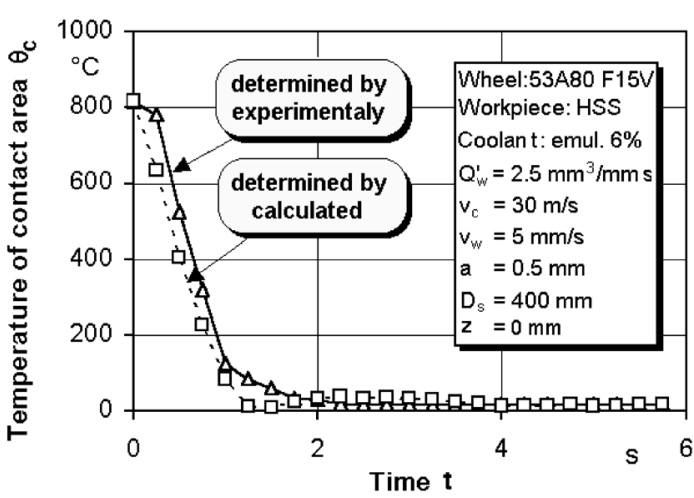

Fig. 11. Temperature change over time in the wheel/workpiece interface

\section{CONCLUSIONS}

Based on this investigation, the following conclusions can be made:

- The proposed analytical model of the thermal state in creep-feed grinding very well describes the real state;

- Analytical inverse heat conduction problem allows approximation of the temperature field in the workpiece surface layer and heat flux density distribution in the wheel/workpiece interface;

- The inverse problem was solved using the method of finite differences in implicit form;

Table 1. Optimal creep-feed grinding conditions, computed by extreme case of inverse method

\begin{tabular}{|c|c|c|c|c|c|c|c|}
\hline \multirow{2}{*}{$\begin{array}{l}\text { Coefficient of } \\
\text { temperature } \\
\text { conductivity } \\
\quad a\left[\mathrm{~m}^{2} / \mathrm{s}\right]\end{array}$} & \multirow{2}{*}{$\begin{array}{c}\text { Max. heat } \\
\text { flux density } \\
q_{\max } \\
{\left[\mathrm{kW} / \mathrm{m}^{2}\right]} \\
\end{array}$} & \multicolumn{3}{|c|}{$\begin{array}{c}\text { Elements of optimal grinding } \\
\text { conditions }\end{array}$} & \multicolumn{3}{|c|}{ Output process parameters } \\
\hline & & $v_{c}[\mathrm{~m} / \mathrm{s}]$ & $v_{w}[\mathrm{~mm} / \mathrm{s}]$ & $a[\mathrm{~mm}]$ & $\begin{array}{c}Q_{w}^{\prime} \\
{\left[\mathrm{mm}^{3} / \mathrm{mm} \cdot \mathrm{s}\right]}\end{array}$ & $h_{m}[\mu \mathrm{m}]$ & $v_{e} / v_{w}$ \\
\hline $4 \cdot 10^{-6}$ & 6700 & 30 & 12.14 & 0.207 & 2.515 & 0.084 & 2472 \\
\hline$(4+0.003 \cdot \theta) \cdot 10^{-6}$ & 5550 & & 11.04 & 0.171 & 1.693 & 0.063 & 2717 \\
\hline $6 \cdot 10^{-6}$ & 4300 & & 9.53 & 0.128 & 1.216 & 0.041 & 3149 \\
\hline $10 \cdot 10^{-6}$ & 4050 & & 9.46 & 0.126 & 1.189 & 0.039 & 3172 \\
\hline \multicolumn{3}{|c|}{$\begin{array}{l}\text { Machining conditions: } \\
\text { Wheel: } 58 \text { A80 F15V Coolant: Emul. } 6 \% \\
\text { Workpiece: HSS } \quad D_{S}=400 \mathrm{~mm} \\
\end{array}$} & \multicolumn{5}{|c|}{$\begin{array}{l}\text { Input parameters: } \\
\begin{array}{l}\xi=\theta(x, t) \text { for } z=1 \mathrm{~mm} ; \theta_{c}=550{ }^{\circ} \mathrm{C} ; k_{s m}=20.34 \cdot h_{m}-0,73 \mathrm{kN} / \mathrm{mm}^{2} \\
\lambda=21.378+0.0275 \cdot \theta \mathrm{W} / \mathrm{m}{ }^{\circ} \mathrm{C} ; \Delta x=0.5 \mathrm{~mm} ; \quad \Delta t=0.25 \mathrm{~s}\end{array}\end{array}$} \\
\hline
\end{tabular}


- For computation of the heat loading of the workpiece surface layer, it requires accurate experimentally obtained temperature distribution at a single point within the workpiece;

- Analytically obtained temperature field in the workpiece surface layer largely agrees with experimental results;

- The optimal control of heat loading in creepfeed grinding allows the parameters of heat source to be kept within limits which guarantee functional properties of the finished part;

- Extreme case of inverse heat conduction problem in creep-feed grinding allows reliable calculation of optimal cutting conditions.

\section{REFERENCES}

[1] Kopac, J., Krajnik, P. (2006). Highperformance grinding - A review. Journal of Materials Processing Technology, no 175, p. 278-284.

[2] Demetriou, M.D., Lavine, A.S. (2000). Thermal aspects of grinding: the case of upgrinding. Journal of manufacturing science and engineering, vol. 122, p. 605611.

[3] Guo, S., Malkin, S. (1994). Analytical and experimental investigation of burnout in creep-feed grinding. Annals of the CIRP, vol. 43, p. 283-286.
[4] Gostimirovic, M., Kovac, P. (2008). The Thermal state of the workpiece surface layer during productivity grinding. Journal for Science, Research and Production, vol. 8, p. 55-61.

[5] Rowe, W.B. (2001). Thermal analysis of high efficiency deep grinding. Journal of Machine Tools and Manufacture, no. 41, p. 1-19.

[6] Shaw, M.C. (1994). A production engineering approach to grinding temperatures. Journal of Materials Processing Technology, vol. 44, p. 159-169.

[7] Ozisik, M.N., Orlande, R.B. (2000). Inverse heat transfer: fundamentals and applications. Taylor \& Francis, Philadelphia.

[8] Alifanov, O.M. (1994). Inverse heat transfer problems, Springer Verlag, Berlin.

[9] Gostimirovic, M., Kovac, P., Sekulic, M., Savkovic, B. (2009). Inverse task solution of heat conduction in grinding process. $10^{\text {th }}$ International Conference on Flexible Technologies, p. 236-240.

[10] Kim, H.J., Kim, N.K., Kwak, J.S. (2006). Heat flux distribution model by sequential algorithm of inverse heat transfer determining workpiece temperature in creep feed grinding. Journal of Machine Tools and Manufacture, no. 46, p. 2086-2093. 